\title{
Breathe's future secure: thank you for your support!
}

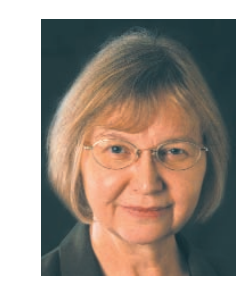

Patricia L. Haslam

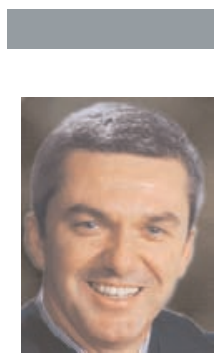

Jean-Luc Eiselé

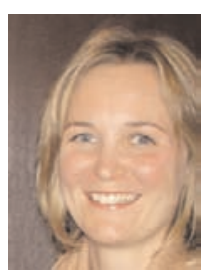

Pippa Powell
The new educational journal of the Society, which was successfully launched on a trial basis in September 2004, was approved by the Executive Committee in Rome on February 3, 2006, and will now be a permanent publication of the ERS.

The aim of Breathe has always been to provide quality peer-reviewed and up-to-date educational material to respiratory specialists in their daily practice. It was not intended to be a scientific journal, but rather a means to make the rich educational resources of the ERS freely available to all ERS members and ERS Congress attendees. It was developed in response to a need for new education initiatives within respiratory medicine in Europe and as a means to provide CME credits.

\section{A short history}

In 2003, background research was commissioned on the need for an educational journal, before the decision was made to begin publishing Breathe. This research included the production of a trial issue and the distribution of an accompanying questionnaire to ERS members from several countries. The feedback from this trial was used to help shape the aims and contents of Breathe at the beginning and to define the target audience.

Breathe was launched at the ERS Congress in Glasgow in 2004. Since then, one issue has been produced each quarter, resulting in 7 complete issues.

In its trial 18-month period, Breathe has undergone several changes and improvements and all indicators show a positive development. The journal is attracting more advertising and, hence, income is steadily increasing. This allows the journal to be sent to 15,000 respiratory professionals and to be accessible on the web for all for free. The number of spontaneous submissions to the journal is growing, which has helped to raise the quality of the material in Breathe. More people have been requesting CME credits each issue, demonstrating the increasing need of our readership for enduring CME material.

\section{Readers feedback}

In December 2005, Breathe sent an online survey to all of its readers to ask your opinion on the future of the journal. We would like to give our sincere thanks to all of you who completed this survey. More than 1,000 of you replied, and provided the Editors and the Executive Committee with very encouraging feedback.

- Educational quality was rated good or excellent for the editorials (91\%), reviews $(95 \%)$, case presentations (89\%) and hot topics (93\%).

- $94 \%$ of respondents rated the scientific quality as good or excellent.

- Articles were all found to be useful (92\%) and well balanced (91\%).

- All aspects of the presentation of Breathe were rated good to excellent (94\%).

- $96.5 \%$ of respondents said Breathe should continue after its trial period.

\section{You made it possible}

This decision of the Executive Committee was supported by the excellent feedback received over the last year on the quality and the educational value of the publication. Your positive feedback and your support was a clear vote.

Launching a new journal requires the input and contribution of many talented and expert colleagues. We would like to mention the Editorial Advisory Board (Sherwood Burge, Alexander Chuchalin, Robert Loddenkemper, William MacNee, Klaus Rabe, Josep Roca, Emiel Wouters), the Last Chief Editor of the European Respiratory Topic (ERT), Nicolino Ambrosino, who accomplished the successful merger of the 


\section{EDITORIAL}

ERT into Breathe during 2004-2005, and the ERS School Assembly Secretaries 2004-2006 (Nicolino Ambrosino, Stefano Nava, Monica Spiteri, Elisabeth Brambilla, Patrick Levy, Peter Calverley, Elisabeth Bel, Mario Cazzola, Isabella Annesi Maesano, Christina Gratziou, James Paton, Andrew Bush, Monika Gappa, Gilbert Massard, Emilio Canalis, Frans de Jongh, Francesco Blasi and Roberto Cosentini). Our thanks also goes to all reviewers, and also to the authors, who have contributed to the journal and worked so hard to make their material educationally focused.

The Executive Committee congratulated the School for this initiative, in particular the dedicated work of Kai-Hakon Carlsen (launching Editor) and Patricia L. Haslam (School Chair and current Editor), and the Managing Editors, for the fantastic job done over the last 3 years to create, develop and successfully nurse this new venture of the ERS.
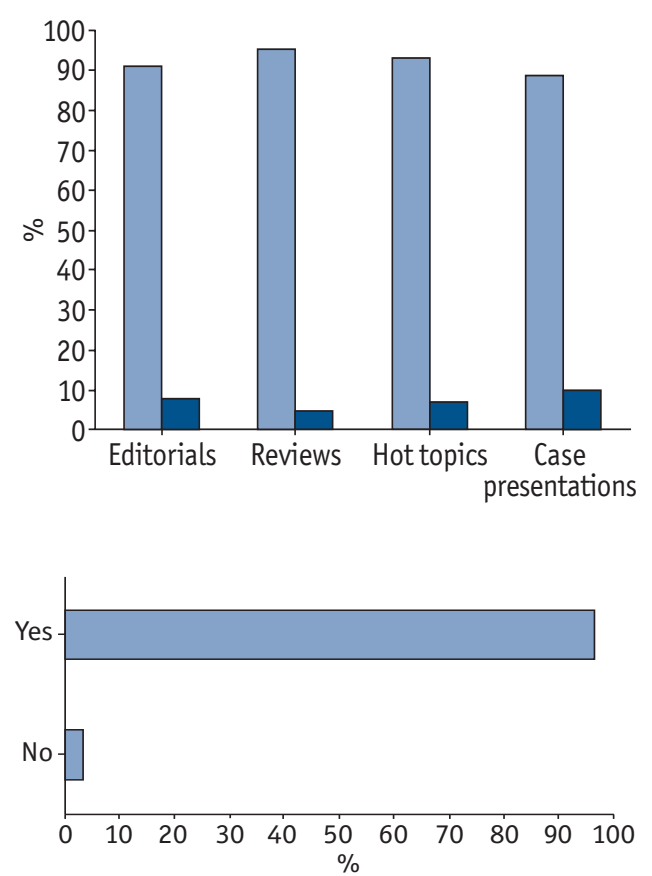

Survey feedback of the educational quality of Breathe.

Excellent/good

Fair/poor

\section{The team behind Breathe}

A new journal cannot be launched without the support and the work of dedicated staff. It is my pleasure to thank the ERS staff both in Lausanne and Sheffield, as well as our partners who contributed to the success of Breathe.

Pippa Powell and Jean-Luc Eiselé (Managing Editors); Myriam Hofer (Alinea Edition) and Lee Dodd (ERSJ; Graphic design); Alan Cole, Alexandra Bonazza and Fiona Cook (Advertisement); Elin Reeves and Catherine Biles (Technical editing); Jan Turnbull and Christine Schmid (Photography); and Linda Arnold, Werner Bill and Archie Turnbull (ERS).

Patricia L. Haslam, Breathe Chief Editor

Survey feedback from the question: "Should Breathe continue after its trial period?" 